\title{
MÁS ALLÁ DE LA REGLA DE ORO: \\ LAS OTRAS RESTRICCIONES CONSTITUCIONALES AL PODER FISCAL Y PRESUPUESTARIO'
}

\author{
Beyond the Golden Rule: The other constitutional \\ constraints to the fiscal and budgetary power
}

\author{
GABRIEL MORENO GONZÁLEZ \\ Universidad de Valencia \\ Gabriel.Moreno-Gonzalez@uv.es
}

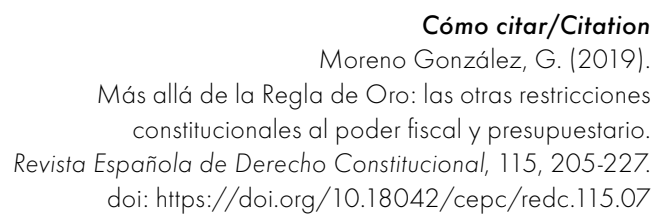

Resumen

Al calor de la constitucionalización de la estabilidad presupuestaria y su teorización, se ha ido configurando una serie de mecanismos ajenos a la misma que tienden a reforzar sus objetivos desde parámetros institucionales de diferente calado. La utilización de instrumentos de democracia semidirecta para la determinación de las políticas fiscales, el establecimiento de fondos de reserva o la creación de órganos independientes de control presupuestario con poder de veto sobre el Parlamento constituyen algunos de los elementos clave de una nueva concepción de la constitución económica que hunde sus raíces en la experiencia norteamericana y en las contribuciones académicas de la llamada economía constitucional.

1 Estudio realizado en el marco del proyecto de investigación del Ministerio de Educación, Cultura y Deporte DER2017-83596-R. Entidad solicitante: UCLM. Centro: Facultad de Derecho de Albacete. Título: «Democracia y solidaridad en las integraciones económicas». IP1: José Luis García Guerrero. IP2: María Luz Martínez Alarcón. 


\title{
Palabras clave
}

Estabilidad presupuestaria; economía constitucional; democracia semidirecta; gobernanza económica.

\begin{abstract}
With the constitutionalization of the balanced budget and its theorization, a set of mechanisms have been making in order to deploy different institutionals answers. The use of semi-direct democracy instruments for the determination of fiscal policies, the establishment of "Rainy Day Fund" or the creation of independent budgetary bodies with veto power over the Parliament, are some of the key elements in the new conception of the economic constitution. The North American experience on the matter and the academic contributions from the school of Constitutional Economy foster the new paradigm.
\end{abstract}

\section{Keywords}

Balance budget rule; constitutional economy; semi-direct democracy; economic governance. 


\section{SUMARIO}

I. INTRODUCCIÓN. II. EL CONTEXTO DE LA ECONOMÍA CONSTITUCIONAL Y LA REVOLT TAX. III. LA DEMOCRACIA SEMIDIRECTA PARA PROTEGER LA CONSTITUCIÓN ECONÓMICA. IV. LAS EXCEPCIONES PROCEDIMENTALES EN TORNO A LAS DECISIONES FISCALES Y PRESUPUESTARIAS. V. LOS RAINY DAY FUNDS O FONDOS DE RESERVA VI. LAS INSTITUCIONES INDEPENDIENTES DE CONTROL PRESUPUESTARIO: EL DERECHO DE VETO SOBRE EL PARLAMENTO. VII. CONCLUSIONES. BIBLIOGRAFÍA.

\section{INTRODUCCIÓN}

La estabilidad presupuestaria fue recibida al más alto nivel en el ordenamiento español en medio de cierta estupefacción académica (y política) y de la ausencia, nada extrańa dada la celeridad con que se aprobó la reforma, de estudios integrales que analizaran las repercusiones jurídicas que su constitucionalización conllevaba. Hoy, transcurrido el tiempo prudencial que permite la distancia de la reflexión, podemos contar ya con ellos, tanto en España como a nivel europeo (Adams, Fabbrini y Larouche, 2014, inter alia), y servirnos, por tanto, del bagaje doctrinal desplegado que suele ser, a su vez, trasunto teórico de la experiencia acumulada.

No obstante, la dificultad de acercarnos desde el derecho constitucional a categorías que, aun llevadas a la máxima norma, no dejan de provenir del campo de la economía ha sembrado de incertidumbre el alcance mismo de las proyecciones de nuestra disciplina sobre la materia, habiendo incluso autores que niegan cualquier análisis jurídico-constitucional de sus efectos (Elster y Slagstad, 1988). Lejos de tales maximalismos, sin embargo, el inconveniente persiste y aun se refuerza debido a las, a estas alturas inexplicables, también persistentes reticencias que desde la doctrina jurídica se vierten sobre otros campos de estudio dentro de las ciencias sociales (y la economía lo es y está en ellas). En el lado opuesto, por el contrario, podemos observar cómo ilustres economistas se han aventurado sin ambages en las categorías constitucionales y cómo, incluso, se ha llegado a crear una verdadera escuela, la de la economía constitucional, que aúna ambas perspectivas y cuyos integrantes no han dudado en entrar a las procelosas aguas de la teoría constitucional, la teoría del Estado y la filosofía política.

Este cúmulo de circunstancias quizá explique, por tanto, la confusión que suele imperar a la hora de tratar las «nuevas» restricciones constitucionales 
al poder fiscal y presupuestario de los Estados, aupadas y amparadas por los recientemente perfeccionados mecanismos de gobernanza económica en la Unión Europea (Embid Irujo, 2012). La estabilidad presupuestaria y la sostenibilidad financiera son los dos grandes principios económicos que han sido juridificados tanto en ellos como en aquellas, presidiéndolos e irrumpiendo en los ordenamientos nacionales, a pesar de lo cual siguen siendo confundidos e integrados en una única parte del binomio, como es la estabilidad presupuestaria y sus normas (Balanced Budget Rules, en adelante, BBR). Y es que esta, por la potencialidad de la caja de herramientas que sus previsiones despliegan, así como por la urgencia de su cumplimiento y observancia en el medio plazo dada la gravedad de la crisis europea, ha tendido a monopolizar todos los discursos y a autoextenderse más allá, alrededor de una serie de instrumentos que, a priori, le son ajenos. A pesar de la loable separación que nuestra Ley Orgánica de Estabilidad Presupuestaria y Sostenibilidad Financiera realiza, esta última suele verse, como decimos, integrada en la primera, cuando la estabilidad presupuestaria se refiere al déficit y la exigencia de su contención (en cifras cercanas al $0 \%$, indexadas al PIB) y la sostenibilidad, por su parte, se predica de los niveles de deuda pública para evitar su extralimitación. La deuda, claro está, sirve para financiar el déficit, y la vinculación entre una y otro es indiscutible, pero jurídicamente son dos principios separados que despliegan efectos diferentes a pesar de que, en el fondo, persigan la consolidación económica de las cuentas públicas.

Su juridificación al más alto nivel ha venido presidida por el refuerzo de la gobernanza económica en los tratados de la Unión y, sobre todo, por la adopción de un polémico tratado, dada su naturaleza intergubernamental, como el de Estabilidad, Coordinación y Gobernanza (Linde Paniagua, 2012: 87-104). La obligación de constitucionalizar la estabilidad presupuestaria que este incorpora para los Estados miembros se ha visto reflejada en sucesivas reformas constitucionales, aunque en el caso de la española se adelantara y anticipara la previsión (2011). Reformas constitucionales que, por su parte, han abierto la cuña en el ordenamiento para que se subordine al nuevo principio a través de las leyes de desarrollo y de una nueva arquitectura de la estabilidad presupuestaria que afecta, incluso, a las competencias de las entidades subestatales (Gorospe Oviedo, 2012: 339-372; Guerrero Vázquez, 2016).

La idea de llevar a los textos constitucionales las reglas de estabilidad presupuestaria no es, sin embargo, tan nueva como pareciera. La experiencia estadounidense, donde los Estados federados incorporan desde mediados del XIX tal restricción en sus normas fundamentales, ilustra un recorrido teórico y empírico más rico y complejo del que se tiende, en ocasiones, a mostrar en Europa. Complejidad a la que hay que añadir la utilización de mecanismos 
constitucionales de limitación del poder fiscal y presupuestario que van más allá de la estabilidad presupuestaria per se, pero que, anejos a esta y constitucionalizados a su calor, han sabido hacerse un espacio nada despreciable en la configuración de las respectivas constituciones económicas. La aplicación de instrumentos de democracia semidirecta, la petrificación de las bases imponibles, el establecimiento de fondos de reserva, la exigencia de mayorías cualificadas en la adopción de determinadas políticas fiscales o presupuestarias o la creación, en el marco institucional, de organismos independientes de control económico, reflejan una nueva realidad que desborda a la previsión clásica de la Golden Rule y que se inserta doctrinalmente, además, en las contribuciones que desde la economía constitucional se han venido realizando. Aunque muchos de estos mecanismos hunden sus raíces en las respuestas institucionales que los Estados tuvieron que afrontar tras diversas coyunturas económicas, aquellas se han venido enmarcando desde los años setenta en un contexto de renovado interés por la limitación constitucional del poder económico estatal que, a su vez, se fundamenta en una concepción propia y elaborada del constitucionalismo y del papel que deben jugar las normas fundamentales en el aseguramiento, prefijado, de un determinado modelo económico.

A continuación analizaremos, por ende, las bases teórico-constitucionales de la economía constitucional y de la Revolt Tax en Estados Unidos, donde se impulsaron estos nuevos instrumentos, para, desde ellas, abordar las restricciones al poder fiscal y presupuestario que desbordan las previsiones de las BBR y que, con el objetivo de complementarlas, constituyen un nuevo corpus en la constitución económica necesitado de estudio. La elección de Estados Unidos como marco de referencia no es baladí: ha sido en este país donde tanto la teorización de los nuevos mecanismos constitucionales como su materialización han llegado más lejos, pudiendo encontrar en sus estados federados una rica experiencia que ha de servirnos de parámetro de estudio. La referencia final al caso húngaro no solo se justifica por la entidad, única, de la innovación incorporada a su normal fundamental en el plano institucional, sino por la cercanía europea de su propia realidad constitucional, que nos recuerda la posibilidad de que los mecanismos aquí analizados desembarquen en el viejo continente.

\section{EL CONTEXTO DE LA ECONOMÍA CONSTITUCIONAL Y LA REVOLT TAX}

Es común ya afirmar que el auge del neoliberalismo en los años setenta vino acompańado de un descubrimiento paralelo de las tesis que, elaboradas 
lenta y laboriosamente durante los lustros anteriores, reciben el nombre de economía constitucional (Escalante Gonzalbo, 2016). Los estudios de James Buchanan, premio Nobel de Economía en 1986, presiden esta escuela, cuyo centro neurálgico radica(ba) en Virginia, y cuyo ideario se focaliza en la centralidad que la norma constitucional tiene y ha de tener en la configuración del modelo económico (Puy Fraga, 1996; Casas Pardo, 2011). Si la escuela ordoliberal alemana había supuesto el primer paso en el giro copernicano del liberalismo hacia el Estado, los planteamientos de Buchanan et al. redirigen el rumbo hacia la Constitución como punto de convergencia de todas sus contribuciones (Moreno González, 2017a: 57-88).

Partiendo de su radical individualismo metodológico, Buchanan considera que la esencia de la democracia no reside en el libre juego de la alternancia entre mayorías y minorías, sino en el respeto escrupuloso de la libertad individual. Recuperando el paradigma neocontractualista, tan en boga en los setenta (Vallespín, 1985), funda el Estado en el consenso unánime, o cercano a la unanimidad, de los ciudadanos, de ahí que rechace de plano la posibilidad de que existan robustos mecanismos de redistribución de la riqueza (Brennan y Buchanan, 1987: 29; Buchanan, 2009: 68 y 74). Si la libertad individual ha de ser el criterio rector, quienes se encuentren en las posiciones más privilegiadas de la escala socioeconómica nunca permitirán que parte de su riqueza se transfiera a las clases más desfavorecidas, imposibilitando con ello la adopción de un acuerdo fundacional. Este, para existir, necesita el consenso, en el que sí pueden encontrarse, no obstante, el reconocimiento de bienes públicos o de débiles instrumentos redistribuidores o de justicia, puesto que la necesidad de llegar a un acuerdo para salir de la violencia inherente al estado de naturaleza puede forzar transacciones de compromiso. Sin embargo, estas nunca llegarán tan lejos como para poder subvertir el orden de distribución inicial, algo que sí se contempla desde el Estado social, ya que ello supondría la pérdida del consenso alcanzado (Buchanan, 1975: 121-126).

Esta especie de velo rawlsiano ha de proyectarse en el momento posconstitucional si, desde el compromiso constituyente, se quieren seguir manteniendo las posiciones de partida lejos de cambios radicales en la distribución de la riqueza. Y para ello la Escuela de Virginia encuentra en los mecanismos constitucionales de gobierno económico los mejores instrumentos para la consolidación y protección del statu quo y la consiguiente garantía del orden democrático consensual. Como quiera que la Constitución es la norma más legitimada, la norma en la que se concentra el esfuerzo constituyente del consenso inicial y lo refleja, las preocupaciones de este se verterán en ella para tener virtualidad más allá del momento fundacional. El temor a la redistribución se ve así transmutado en las limitaciones constitucionales al poder fiscal 
y presupuestario del Estado con el objetivo de que el mismo, una vez cobre vida y al ser pilotado por las mayorías sociales alternantes en el poder, no pueda dirigir sus energías redistributivas contra las minorías, menoscabando así su libertad. La petrificación de las bases imponibles en la Constitución, la indexación de los tributos en la misma o la exigencia constitucional de mayorías cualificadas para la elevación de impuestos son algunas de las medidas que se proponen desde Virginia para hacer frente, gracias a la especial normatividad de la Norma Fundamental y su posición preeminente en el ordenamiento, a las potencialidades más socializantes de la democracia (Brennan, 1981: 466 y ss.).

Al mismo tiempo, y como quiera que las mayorías sociales son las que tienen más posibilidades de alcanzar siempre el poder y suelen poseer además mayores pretensiones redistributivas, el Estado se ve en la tesitura de ser gobernado con un criterio expansionista, al servicio de los intereses de tales mayorías. La Administración pública, su brazo ejecutor a través de las múltiples prestaciones, tiende por ello irremisiblemente a su expansión constante, a lo que hemos de añadir los propios intereses de los burócratas al mando. Si las personas siempre son propensas a maximizar sus beneficios actuando racionalmente, dicen desde la economía constitucional, quienes dirigen las Administraciones querrán en todo momento que los organismos que presiden crezcan y se consoliden para ver así aumentado su potencial de influencia y prestigio. Para evitar esta doble predisposición del Estado y la Administración a expandirse sin freno y a servir sin cortapisas a las exigencias redistributivas de las mayorías, se hace necesario constitucionalizar al lado del poder fiscal la regla de la estabilidad presupuestaria, cuya conjunción con el primero puede llegar a atar eficazmente, cual Ulises, la acción intervencionista del Estado (Puy Fraga, 1996: 273 y ss.).

Pero estas cadenas constitucionales, para funcionar íntegramente, necesitan ser incorporadas a las normas fundamentales en paralelo. De nada vale constitucionalizar las bases imponibles de determinados impuestos si se permite, dice Buchanan, que el Estado pueda gastar sin límites, y, viceversa, no tendría mucho sentido restringir el gasto público sin dificultar la elevación de impuestos. Desde la óptica de la economía constitucional, ambos ámbitos han de complementarse en conjunción, pues de lo contrario el objetivo que se persigue desde sus categorías, la limitación de la potencialidad redistributiva del Estado, quedaría yermo. He aquí una de las primeras y más firmes vinculaciones teóricas de la estabilidad presupuestaria a un set de reglas fiscales y presupuestarias que, aun siendo en un principio ajenas a la primera, tienden a aparecer contiguamente a ella cuando no, directamente, a ser confundidas con la misma. 
Y es en el contexto político, económico y social de los setenta en Estados Unidos cuando estas ideas y construcciones de Buchanan y su Escuela de Virginia alcanzan cierto predicamento y salen a la luz de la política diaria. La Revolt Tax o rebelión del contribuyente encontró asidero teórico en las categorías de la economía constitucional y en el campo abonado del neoliberalismo teórico (Brennan y Buchanan, 1987: 51 y ss.). Claro que ello no quiere decir que sean tales categorías e ideas las que determinaran y propiciaran el movimiento, sino que más bien se dio una interdependencia mutua a la que el propio Buchanan contribuiría desde las tribunas de los medios, la prensa y los artículos doctrinales. La desafección ciudadana para con el Estado federal en esta época, en parte debida a la crisis del petróleo y el desastre de Vietnam, pero en un margen nada despreciable derivada también del descrédito general de lo federal por parte de los estados y sus centros de opinión, se unió en torno a un movimiento ciertamente novedoso y transversal que exigía la limitación constitucional del poder fiscal y presupuestario de Washington y, al tiempo, de los propios estados (Morgan, 1988: 422 y ss.). No obstante, las reiteradas iniciativas para consagrar la estabilidad presupuestaria a nivel federal, desde los intentos de convocar una convención constitucional a los de aprobar una enmienda constitucional en el Congreso, fracasaron estrepitosamente por culpa, entre otros factores, de la propia y sui generis configuración de los checks and balances norteamericanos.

Por el contrario, el ímpetu del contribuyente organizado para salvaguardar su property frente a los mecanismos redistribuidores propios de un Estado social ya por entonces en franca retirada tuvo su eco más relevante en el contexto estatal. $\mathrm{Y}$ es aquí donde cobra especial importancia el propio devenir histórico del constitucionalismo económico de los estados que conforman la Federación, tan poco estudiado aún hoy por la doctrina constitucional (Moreno González, 2017b: 247-288). Hay que recordar que, al contrario de lo que muchos presuponen, las contribuciones de la economía constitucional y las demandas de la Revolt Tax no partían ex nibilo, puesto que el siglo XIX había sido generoso en la anticipación de algunos de los mecanismos propuestos o resucitados en los setenta. La crisis económica 1837 había provocado, entre otras consecuencias, la quiebra de numerosos estados que, con una capacidad tributaria nimia, se habían aventurado en la financiación de grandes obras e inversiones públicas. Para contrarrestar la pérdida de credibilidad en los mercados internacionales de deuda, los estados fueron modificando sus constituciones e incorporando instrumentos como la «deuda garantizada» o principios como el de estabilidad presupuestaria que, a pesar de sus múltiples concreciones, fueron siendo constitucionalizados en la práctica totalidad de unidades subfederales (Kiewiet y Szakaly, 1996). No obstante, la mayor parte 
de estas previsiones respondían a coyunturas concretas o eran fácilmente evadidas, y su objetivo no era per se limitar un Estado social que ni siquiera, entonces, existía. Los estados tenían una débil capacidad tributaria y presupuestaria, correlativa a las pocas funciones que, respecto a la segunda mitad del siglo $\mathrm{xx}$, desempeńaban.

Así, la defensa buchaniana de los mecanismos de democracia semidirecta para dificultar la expansión del poder fiscal y la utilización de aquellos por parte de los protagonistas de la Revolt Tax en los setenta se desenvuelven en un contexto normativo en el que tales mecanismos ya existían de manera profusa en las realidades estatales. La novedad reside en que la propensión de la economía constitucional a su utilización para garantizar la propiedad, lato sensu, de los contribuyentes, es correlativa a la consideración individualista y consensual de la propia democracia que posee la escuela. Las decisiones en materia de política económica y fiscal cuanto más se acerquen al ideal de la unanimidad y más representativas sean de los intereses del conjunto de los ciudadanos, mayores cuotas de seguridad aportarán al statu quo. $\mathrm{O}$, al menos, esa es la valoración de la que se parte.

\section{LA DEMOCRACIA SEMIDIRECTA PARA PROTEGER LA CONSTITUCIÓN ECONÓMICA}

Algunos autores no han dudado en calificar a los estados federados de EE. UU. como «laboratorios de democracia» (Gardner, 1996: 475-491; Tarr, 2001), pues si bien la Constitución federal de 1787 es la que ha centrado los análisis de naturaleza jurídico-constitucional sobre el país norteamericano, en las realidades de sus entidades subfederales es donde podemos encontrar las previsiones más innovadoras e interesantes para las perspectivas de renovación del derecho constitucional contemporáneo. En este sentido, no es baladí que la Carta Magna federal no prevea ningún mecanismo de democracia semidirecta, por cuanto refleja las inquietudes, ideas e intereses de los Founding Fathers, muy temerosos de la tiranía de las mayorías y de la centralización abusiva del poder que podría derivarse de su legitimación directa (Federalista n. $\left.{ }^{\circ} 10\right)$. De ahí que el espacio de mayor participación se dejara a las constituciones estatales, donde la tradición republicana y jeffersoniana siempre tuvo mayor resonancia e impacto, y donde además la defensa de la democracia semidirecta no encontraba tantos impedimentos, quizá en la creencia de la inanidad que podían presentar los mismos estados.

De este modo, enmarcados en una tradición de participación y mayor cercanía entre los representantes y los representados que hundía sus raíces en 
los primitivos covenants de la época colonial, los estados federados irían recogiendo desde su nacimiento diversos tipos de mecanismos de democracia semidirecta, algunos de los cuales proceden de las primeras constituciones refrendadas popularmente. En general, estos mecanismos pueden ser agrupados en tres grandes conjuntos: la iniciativa (legislativa o constitucional, directa o indirecta), el referéndum y el revocatorio, aunque la iniciativa popular solo la encontramos desde principios de siglo xx.

El revocatorio o recall, consistente en la destitución de un cargo representativo por la manifestación en ese sentido de la voluntad popular, se predica exclusivamente del ejercicio del mandato, no de previsiones legales o constitucionales susceptibles de aprobación, derogación o modificación por el pueblo, de ahí que no nos interese en el presente caso. La iniciativa y el referéndum, por el contrario, son dos instrumentos que se han utilizado profusamente para delimitar el ejercicio del poder fiscal y presupuestario de los estados al calor de la regla de estabilidad presupuestaria constitucionalizada en estos, como veremos.

La iniciativa (initiative) es el cauce a través del cual los ciudadanos de un estado pueden comenzar un procedimiento legislativo tendente a la aprobación de una ley o, en el caso de las reformas constitucionales, el impulso de esta dentro de los márgenes y los límites establecidos por la propia Constitución. La iniciativa puede ser directa o indirecta, concurriendo en este último caso la voluntad de los representantes en el Parlamento estatal para poder aprobar definitivamente el proyecto presentado. En el caso de la directa, sin embargo, es el cuerpo electoral el que sin intermediarios puede someter a referéndum la proposición que previamente se ha expuesto a la recogida de firmas, previsión que es común en el inicio de toda initiative pero cuyo número varía, ostensiblemente, de un estado a otro.

A pesar de la amplia divergencia de regulaciones estatales, el origen y la expansión de la iniciativa como instrumento de democracia semidirecta podemos encontrarlo en la Progressive Era (1890-1920), donde los cambios estructurales de la sociedad norteamericana, acompańados por un proceso imparable de urbanización e industrialización, dejaron al descubierto la extendida corrupción de los representantes y el mal funcionamiento de las instituciones. Las exigencias de los distintos movimientos y partidos, algunos con un claro proyecto popular, aumentaron la capacidad innovadora de las constituciones estatales, recogiendo en ellas, entre otros instrumentos, la iniciativa, siendo la primera previsión constitucional la de Dakota del Sur (1898) y la primera utilización, la del estado de Oregón (1904) (Munro, 1912). Estamos, pues, ante el más cercano en el tiempo de los mecanismos de democracia semidirecta, pues tanto el referéndum como el recall pueden ser encontrados en las 
constituciones estatales desde la etapa fundacional. Desde el fin del período progresista seminal, sin embargo, el número de iniciativas presentadas sufrió una fuerte caída (Matsusaka, 2004: 5), y no es hasta la década de los setenta, con el impulso de la Revolt Tax mentada, cuando recuperaron vigor y volvieron a ser utilizadas con mayor intensidad, sobre todo en estados como los de California, Washington o los del Medio Oeste (Asatryan et al., 2016: 11).

Cabe destacar, asimismo, que la iniciativa no solo se reduce al nivel estatal, pues desde este se permitió, durante la misma Progressive Era, que los municipios y condados pudieran utilizarla en sus políticas locales, incluidas las tributarias. El primer estado que aprobó dicha posibilidad fue California en 1893 (Matsusaka, 2005a: 189), inaugurando una pauta que en general ha seguido la práctica totalidad de estados, especialmente de nuevo los del Oeste y el Medio Oeste.

California es, precisamente, el paradigma de la democracia semidirecta en Estados Unidos, tanto por la importancia del estado (demográfica y económicamente más relevante que grandes países europeos) como por el papel destacado que han tenido la iniciativa popular y el referéndum en la conformación de las políticas públicas, y muy especialmente las tributarias y fiscales, de las que se ocupan más de la mitad de las iniciativas presentadas desde inicios del siglo xx y en la que la Proposición 13, de 1978, cobra especial relevancia (Matsusaka, 2005b: 251-253).

En efecto, dicha iniciativa ha venido siendo considerada como el paradigma de la Revolt Tax ya mencionada de finales de los setenta y, desde luego, uno de sus principales bautismos de fuego (Kuttner, 1980) en el que, además, Buchanan y destacados miembros de su escuela vieron reflejadas sus principales contribuciones (Buchanan y Brennan, 1987: 51). El clima de desafección política que mencionábamos tuvo un impacto muy notable en la California de entonces, donde a la elevación continua del gasto público se añadieron casos de corrupción a nivel municipal que lastraron la confianza de los ciudadanos en las Administraciones y en su capacidad para gestionar los tributos, los cuales comenzaron a verse como abusivos y desproporcionados. Tras una campaña muy exitosa, las agrupaciones de contribuyentes californianos consiguieron someter a referéndum, mediante una initiative, la constitucionalización de límites infranqueables a la imposición fiscal. En concreto, la Proposición 13 implicaba la reforma de la Constitución para que impidiera que los poderes públicos pudieran gravar más del $1 \%$ del valor catastral de los inmuebles (Cain y Noll, 2010).

El referéndum sería ganado con más del $60 \%$ de los votos a favor, y la Proposición 13 se convertiría en el art. XIII A de la Constitución de California. En cuanto buque insignia de la Revolt Tax, su influencia ha sido notable 
en la consecución de iniciativas de similar naturaleza en el resto de estados, así como, en general, en las pretensiones de limitar constitucionalmente el margen tributario del que disponen los Parlamentos y Gobiernos estatales de EE. UU. (O’Sullivan et al., 1999).

Pero no solo las iniciativas populares tienen por objeto la constitucionalización de límites explícitos al poder tributario. Algunas, como la famosa Proposición 98, de 1988, y también de California, se han aprobado con el objetivo expreso de imponer una obligación constitucional de gasto en determinados ámbitos considerados esenciales, como la educación; obligación que solo puede ser suspendida o levantada por $2 / 3$ de cada una de las Cámaras de la legislatura estatal. Y aunque, como indica Matsusaka, el porcentaje de gasto que está constitucionalizado no es muy relevante y permite al estado seguir teniendo un margen elevado de acción presupuestaria, la posibilidad de utilizar instrumentos de democracia semidirecta para restringir este, y hacerlo además desde la Carta Magna, es común a la mayoría de estados de la Federación (Matsusaka, 2005b: 254).

El procedimiento de iniciativa en California es similar al de los otros estados, requiriendo la proposición un número determinado de firmas que pueden activar o bien la aprobación del Parlamento estatal o bien la convocatoria de un referéndum aprobatorio de la norma impulsada. En el caso californiano el número de firmas necesarias es del $5 \%$ del censo electoral, pero la cantidad varía en los estados, desde Dakota del Norte (2\%) a Wyoming $(15 \%)$. Una diferencia notable que sí podemos encontrar en el caso californiano es que aquellas proposiciones que se deriven de una iniciativa popular solo podrán ser modificadas o derogadas, nuevamente, por la acción directa del cuerpo electoral y nunca por la legislatura o el gobernador estatales (ibid.: 251).

Al mismo tiempo, la democracia semidirecta ha sido también utilizada para refrendar reformas constitucionales que afianzan la estabilidad presupuestaria. Aunque esta, siguiendo el ejemplo californiano, fuera ya una obligación en la Constitución estatal desde mediados del XIX, se predicaba única y exclusivamente del proyecto de presupuestos que enviara el gobernador, pudiendo luego la legislatura estatal desequilibrar el presupuesto final. Sin embargo, mediante referéndum se decidió en 2004 (Proposición 58) una reforma constitucional para reforzar la Balanced Budget Rule y proyectar el conjunto de sus obligaciones también sobre el presupuesto definitivo, consolidando así la llamada Regla de Oro en el texto fundamental.

Por otro lado, el referéndum es necesario en determinados estados, como Pensilvania (art. VIII.7), para poder sortear las exigencias de sostenibilidad presupuestaria y autorizar las emisiones de deuda, con lo que ello conlleva de 
petrificación del margen de acción económica de los Gobiernos y las legislaturas estatales. La creencia de que mecanismos de democracia semidirecta como el referéndum pueden frenar mejor las tendencias expansionistas e intervencionistas del estado resuena en este tipo de previsiones, muy apoyadas desde la economía constitucional y parte de la doctrina (Kiewiet y Szakaly, 1996: 93).

\section{LAS EXCEPCIONES PROCEDIMENTALES EN TORNO A LAS DECISIONES FISCALES Y PRESUPUESTARIAS}

En múltiples ocasiones, la constitucionalización de la estabilidad presupuestaria o de límites expresos al poder tributario y/o presupuestario de los estados viene acompańada de la exigencia de refuerzos procedimentales para la adopción de determinadas decisiones en esos ámbitos. La regla general en la democracia constitucional para la creación de normatividad es la de la mayoría simple o relativa, siempre que tal creación no afecte a esferas consideradas por el constituyente como merecedoras de especial protección por su excesiva necesidad de garantía y el papel central que ocupan en el ordenamiento. Así, el desarrollo de los derechos fundamentales, su posible suspensión o la organización de las instituciones básicas del Estado suelen precisar mayorías cualificadas con las que se pretende, en último término, reforzar tanto la legitimidad democrática de los cambios como su dificultad. La constitución económica, en cambio, ha solido seguir la pauta general de la mayoría simple, algo que podemos comprobar en la regulación de los contenidos económicos de la Constitución española en su título VII. Las reservas al sector público y la intervención de empresas (art. 128.2), la planificación indicativa de la economía (131), los bienes de dominio público (132), la potestad tributaria (133), la presupuestaria (134) o la emisión de deuda pública (135) tienen reserva constitucional de ley, pero de ley ordinaria. No cabe en ellas aprobar leyes orgánicas o exigir para su adopción mayorías superiores a la simple.

Sin embargo, una de las notas dominantes en la elaboración doctrinal de la economía constitucional es, como apuntábamos más arriba, la consideración del statu quo económico como objeto de especial protección constitucional, protección que ha de revestirse procedimentalmente a través del establecimiento de mayorías cualificadas lo más cercanas al ideal de la unanimidad (Puy Fraga, 1996: 218-267). Para evitar cambios bruscos o transformaciones que alteren radicalmente la distribución inicial de la riqueza amparada en el momento de la unanimidad constituyente y, por ende, menoscaben la libertad individual, Buchanan y el resto de autores de Virginia propugnan la 
mayor petrificación constitucional posible de los mecanismos redistribuidores y de la intervención estatal en la economía. Las mayorías cualificadas para la adopción de decisiones en política económica, junto con la constitucionalización misma de las bases imponibles de los tributos, son algunas de las medidas defendidas y propuestas, medidas que tuvieron cierto eco durante la Revolt Tax y que se incardinaban en el contexto normativo-constitucional estadounidense ya descrito. Así, por ejemplo, la famosa Proposición 13 de California no solo constitucionalizaba un límite rotundo para la elevación de los impuestos inmobiliarios, sino que obligaba a las dos Cámaras del Parlamento estatal, desde la fuerza jurídica de la Carta Magna, a aprobar cualquier tipo de incremento de impuestos, tanto locales como estatales, mediante una mayoría cualificada de $2 / 3$.

Asimismo, las proposiciones de enmienda que se han venido sucediendo desde los setenta para incorporar en la Constitución Federal la regla de la estabilidad presupuestaria han solido acompañarse también de exigencias procedimentales de idéntico sentido y ajenas como tal a la Balanced Budget Rule. De este modo, la enmienda Hatch de 1981, que casi consigue ser aprobada por el Congreso, exigía que cualquier modificación fiscal de la Federación fuera aprobada por mayorías cualificadas (Kyvig, 1995: 112-113). En la enmienda que quizá ha tenido más éxito, y que, aun no siendo nunca aprobada, sigue constituyendo la máxima referencia para las posteriores y los intentos actuales de constitucionalización de la BBR, también aparecían tales exigencias procedimentales. En concreto, la enmienda de 1995 establecía que para la modificación de las bases impositivas se necesitase al menos un $60 \%$ de apoyo en cada Cámara, y para la autorización de la emisión de deuda pública, el consentimiento de 3/5 también, tanto de la Cámara de Representantes como del Senado.

Huelga decir que, en el complejo y sui generis marco institucional norteamericano, donde la democracia de partidos está atenuada por la independencia y autonomía de los representantes públicos y el contundente sistema de checks and balances, tales excepciones procedimentales conllevan una dificultad muchas veces insoslayable. Situación esta última que es directamente rechazada por Buchanan, para quien tales exigencias de mayorías cualificadas son una mera formalidad que no dificulta la adopción de decisiones, al ser para él simplemente procedimientos diferentes al común, pero igualmente reglados (Buchanan, 1995).

Estas excepciones procedimentales no solo se predican, además, de los incrementos impositivos o de la emisión de deuda, puesto que determinadas constituciones estatales prevén también mayorías cualificadas para poder suspender la eficacia de la regla de estabilidad presupuestaria. La Constitución de 
Delaware, por ejemplo, establece en su art. VIII una mayoría muy elevada, de $3 / 4$, para considerar inaplicable en un ejercicio presupuestario concreto la $\mathrm{BBR}$ estatal. Incluso podemos encontrar previsiones constitucionales como la de Michigan (art. IX.15), que, al mismo tiempo que exigen mayorías cualificadas altas ( $2 / 3$ en este caso), imponen la obligación posterior de que los acuerdos que cumplan con dichas mayorías sean ratificados por el pueblo en referéndum. Aquí, pues, a la utilización de restricciones procedimentales se suma el recurso a mecanismos de democracia semidirecta, cuya combinación ha de conllevar, necesariamente, una mayor dificultad y lentitud en la toma de decisiones y una afectación más profunda en el margen de libertad en el que opera la democracia representativa.

En el caso español, la reforma constitucional del art. 135 de 2011 también introduce cambios procedimentales de considerable impacto, y que a veces no han sido lo suficientemente tratados por la doctrina especializada. La Constitución ahora no solo acoge sin ambages la estabilidad presupuestaria como mandato al más alto nivel normativo, sino también la exigencia de que su desarrollo se haga por mayoría absoluta mediante una ley orgánica, rompiendo así la tónica general del título VII y la tradición que nuestro ordenamiento constitucional había guardado en favor de la ley ordinaria. Asimismo, las excepciones a la eficacia de la regla de estabilidad se recogen casuísticamente en el mismo precepto constitucional, cuya concurrencia ha de ser apreciada también por la mayoría absoluta de Congreso de los Diputados. Sin llegar a mayorías aún más cualificadas o la necesidad de un referéndum, como sí establecen algunas constituciones estatales de EE. UU., nuestra Carta Magna hace un guiño a la especial protección jurídica de las relaciones Estado-economía que propugna la economía constitucional.

\section{LOS RAINY DAY FUNDS O FONDOS DE RESERVA}

Sostener los niveles de deuda y déficit públicos en los límites de la disciplina fiscal ante desbalances en los presupuestos solo se puede conseguir mediante cuatro acciones: reducción del gasto, aumento de los impuestos, uso de subterfugios fiscales o utilización de fondos previamente apartados en períodos de superávit. Los conocidos en Estados Unidos como Rainy Day Funds (RDF, en adelante), o fondos de estabilización, pertenecen a esta última categoría, y consisten en la retirada automática de sumas determinadas de dinero y su congelación en fondos apartados que no computan en los presupuestos para, en situaciones de coyuntura económica desfavorable, poder ser utilizados como políticas de estímulo. Lo que se pretende es, por tanto, hacer 
que el gasto público pueda actuar de forma contracíclica en momentos de recesión, cuando los ingresos suelen hundirse, y no coadyuve así a ralentizar la economía.

Esta herramienta presupuestaria, constitucionalizada en la mayor parte de los estados, se popularizó y consolidó en la década de los ochenta con los últimos vaivenes de la Revolt Tax y el auge de las ideas de la economía constitucional junto con el de Ronald Reagan y los republicanos (Wagner et al., 2006: 177-200). Aunque el diseño institucional de los RDF es esencial para comprobar su efectividad normativa, casi todos comparten similares características y están previstos en sede constitucional, desde la que se proyecta su vinculatoriedad para los legisladores estatales (Rodríguez-Tejedo, 2012: 376386). Porque nuevamente es en el nivel subfederal, estatal, donde encontramos este instrumento constitucional de control del poder presupuestario, y no solo por la falta de innovación de la que adolece la Constitución de Filadelfia, sino por la necesidad intrínseca que tienen los estados de acompasar y suavizar los mecanismos constitucionales de estabilidad presupuestaria ya consagrados en sus ordenamientos. Y es que una interpretación strictu sensu de una BBR puede impedirle al estado la adopción de medidas contracíclicas en momentos de recesión, por cuanto estas pondrían en juego la estabilidad presupuestaria para el ejercicio concreto en que se quisieran implementar. De lo contrario, si el mismo nivel constitucional recoge la necesidad de acumular fondos en períodos de superávit o de expansión económica para utilizarlos en momentos de coyuntura negativa, se está consiguiendo sortear la exigencia de equilibrio presupuestario al poder liberar cantidades que aumentan exponencialmente el gasto público por encima de la previsión de ingresos. De ahí que sea en los estados donde las previsiones constitucionales de estabilidad presupuestaria son más rígidas en los que podemos encontrar, al tiempo, los RDF más completos, elaborados y eficaces (Wagner y Elder, 2007: 727). Es más, en estados como California, tal y como hemos visto, donde existen fuertes limitaciones al incremento de la presión impositiva (mayorías cualificadas o prohibiciones expresas), los Rainy Day Funds pueden también ayudar a evitar las consecuencias más lesivas y contraproducentes de tales limitaciones, pues pueden utilizarse fondos adicionales sin necesidad de elevar los tributos para hacer frente a un período de recesión (Poterba, 1994). En este sentido, se puede encontrar una regulación extensa de los RDF de California en el art. 13B de la Constitución estatal, donde se establece la obligación de que todas las entidades públicas del estado, incluido el Gobierno, creen fondos de estabilización.

Al margen de la excesiva discrecionalidad que a veces presentan los RDF en sus propias regulaciones, así como las posibilidades de su manipulación (Rose, 2008), lo cierto y verdad es que sus implicaciones sobre los tiempos 
políticos son evidentes, en la medida en que subordinan estos a los ciclos económicos. Tradicionalmente se ha acusado a la gestión política de la economía de cortoplacista, al considerarse que las necesidades políticas (sobre todo, las que están relacionadas con la reelección) no tienen en cuenta los ciclos a largo plazo que se dan en la economía. El gasto público desproporcionado en períodos cercanos a las elecciones, la falta de previsión económica más allá de los respectivos mandatos o la ausencia total de vínculos hacia el futuro de unos representantes ligados a la inmediatez de sociedades, cada vez más necesitadas de rápidas respuestas, convergen en el vértice de las políticas públicas hasta hacerlas, se dice, insostenibles. La posibilidad de certeza de tales afirmaciones no corresponde a la naturaleza del presente estudio ni de la disciplina constitucional, pero sí las vinculaciones normativas que, desde la altura y aparente inmutabilidad de las normas fundamentales, se establezcan para circunscribir el margen de decisión, discrecionalidad y actuación de los poderes públicos. En este sentido, los RDF se enmarcan en los mecanismos constitucionales de gobierno económico que tienden a reducir jurídicamente, y ex ante, el conjunto alternativo de posibilidades que se le presentarían a los Gobiernos y legisladores en un contexto de mayor libertad (fiscal y presupuestaria), diaria.

\section{LAS INSTITUCIONES INDEPENDIENTES DE CONTROL PRESUPUESTARIO: EL DERECHO DE VETO SOBRE EL PARLAMENTO}

Una de las funciones básicas y seminales de los Parlamentos, a través de la cual los mismos cobraron vida en los albores de la Modernidad, es la de controlar el poder fiscal y presupuestario del Ejecutivo, ya fueren el rey o, en la actualidad, el Gobierno. Legitimar democráticamente las decisiones económicas, por un lado, y cuidar por que estas no se excedan desproporcionadamente y se vuelvan insostenibles, por otro, sustentaban las pretensiones del Legislativo. El principio de legalidad tributaria o la necesidad de que las emisiones de deuda pública fueran aprobadas en sede parlamentaria fueron conquistas frente a la arbitrariedad de los monarcas o los Gobiernos, y aunque se atenuaron con la complejidad y el aumento exponencial de necesidades materiales del Welfare State, siguen apareciendo en nuestras cartas magnas como elementos nucleares de la constitución económica y la división de poderes.

A partir de la crisis del petróleo de los setenta y la irrupción de las corrientes neoliberales (así autodenominadas sin pretensiones peyorativas), se comenzó a hacer un especial hincapié en la necesidad de garantizar la gobernabilidad de los sistemas de democracia constitucional ante el ímpetu y los vaivenes 
populares de los poderes legislativos, trasuntos ellos de las demandas cada vez más insostenibles, se decía, de la ciudadanía (Crozier, Huntington y Watanuki, 1975). El incremento preocupante de los niveles de déficit y deuda públicos, junto con la caída del ideario keynesiano, coadyuvaron a la reconsideración del papel tradicional del Parlamento en el cumplimiento de sus funciones de control. De aquí que se optara en la propia praxis constitucional subsiguiente por reforzar la accountability externa a través, principalmente, de tres medios: los procedimentales, los numéricos o de indexación, y los institucionales.

Los dos primeros ya los hemos analizado en las páginas anteriores, aunque hay que destacar que los numéricos también se refieren no solo al establecimiento de porcentajes indexados al PIB o a otros indicadores para la limitación de la deuda y el déficit (BBR lato sensu), sino a la propia determinación constitucional de una cifra exacta que no puede ser en ningún caso superada por el Estado. Así, la Constitución de Arizona, en su art. IX.5, prevé que el montante total de la deuda pública no supere los 350 millones de dólares. En este sentido el ordenamiento polaco incorpora, también, una novedad muy relevante, la llamada Belka's rule, que impide que el presupuesto crezca año tras año más de un $1 \%$ en términos reales e indexados a la evolución del PIB, descontando la inflación (Adams, Fabbrini y Larouche, 2014: 214).

Lo que ahora nos interesa analizar, sin embargo, son los instrumentos institucionales que se han venido implementando y diseńando para hacer frente a esa aparente disfuncionalidad de la función parlamentaria con el objeto de limitar la acción presupuestaria de los Gobiernos.

Desde el New Public Management, la economía constitucional o las diversas corrientes que integran el nuevo liberalismo, se ha realizado una defensa a ultranza de las Administraciones independientes para garantizar la seguridad de los intereses económicos. No es de extrañar que esa defensa se haya, por tanto, trasladado también al ámbito presupuestario, que ha visto crecer a su alrededor una cantidad innumerable, a ambos lados del Atlántico, de consejos, comités u organismos pseudoindependientes con funciones de consejo, supervisión y recomendación a los Parlamentos. Hasta la respuesta institucional que desde Europa se ha realizado a la crisis económica y de deuda pública iniciada en 2008 no se había, no obstante, llegado a dotar a ninguno de estos órganos del poder de veto presupuestario. En primer lugar, por la ausencia evidente de legitimidad democrática de los mismos, convertidos en especies de eforados con pretensión de tecnicidad pero sin elección popular o control parlamentario dada su independencia; control que, de darse, acabaría con su propia función. En segundo lugar, y no menos relevante, por la naturaleza misma del ámbito de decisión en el que han de operar, pues la política económica general, en la que la presupuestaria posee la mayor centralidad, no 
es una cuestión científica o reducible a parámetros técnicos y neutrales. La proliferación de consejos de política fiscal y presupuestaria en Europa, como consecuencia de la aprobación de los nuevos mecanismos de gobernanza económica y del Tratado de Estabilidad, Coordinación y Gobernanza, ilustra tales dificultades desde el prisma democrático. Aquellos siguen, en buena medida, el ejemplo abierto por Alemania con su Consejo de Estabilidad, cuya tarea es la de supervisar a largo plazo los presupuestos presentados y evitar crisis de sostenibilidad en las finanzas públicas (art. 109 a de la Ley Fundamental). Sin embargo, tal Consejo, como decimos, no está revestido de poderes de veto (Zipfel, 2011).

El cambio sustancial, y que nos sitúa en el nuevo set de previsiones constitucionales en este estudio analizadas, lo ha protagonizado Hungría, con su nueva Constitución de 2011, donde no solo se establece un techo indexado de deuda pública ( $50 \%$ respecto al PIB) o se recoge taxativamente y de forma muy contundente la regla de estabilidad presupuestaria strictu sensu, sino también una nueva institución, el Consejo Presupuestario, completamente independiente $\mathrm{y} . .$. con poder de veto sobre el Parlamento. De acuerdo con el art. 44 de la Constitución, el presidente del Consejo es elegido para un mandato de seis ańos por el presidente de la República, y los otros dos miembros del Consejo son el gobernador del Banco Nacional de Hungría (a su vez, también elegido por el presidente de la República para un mandato de seis años) y el presidente de la Oficina Estatal de Auditoría, elegido por el Parlamento por una mayoría de $2 / 3$ para un período de ¡12 años! El Consejo asume las funciones tradicionales encomendadas a este tipo de instituciones, como la de recomendación, supervisión, consejo y elaboración de informes y dictámenes, pero la Constitución le permite además vetar los presupuestos aprobados por el Parlamento si considera que no cumplen con los objetivos de estabilidad presupuestaria y sostenibilidad fiscal. Si aun así el Parlamento desobedeciera al Consejo y su veto, la Norma Fundamental húngara habilita a la Corte Constitucional a anular los presupuestos (art. 37.4).

De acuerdo con el profesor Varju (2012: 315), la húngara sería la única constitución del mundo que ha creado un órgano independiente con tales poderes sobre el presupuesto. Por su parte, siguiendo a Marek Antôs (Adams, Fabbrini y Larouche, 2014: 214-216), esta novedad institucional conlleva dos peligros susceptibles de crítica. En primer lugar, el Consejo Presupuestario húngaro es revestido de un poder excesivo sobre el Parlamento y, por ende, sobre la voluntad representada de los ciudadanos del país centroeuropeo, a pesar de carecer de la legitimidad directa de estos a través de las elecciones democráticas. La larga duración de sus mandatos, que en uno de sus miembros llega a una cifra desconocida en el ámbito comparado, su completa independencia y autonomía 
ante los órganos democráticos una vez elegidos o la falta de rendición de cuentas de la institución refuerzan sus falencias democráticas.

En segundo lugar, la previsión del art. 3.3 de la misma Constitución húngara obliga al Parlamento a aprobar un presupuesto equilibrado bajo el criterio de la estabilidad presupuestaria impuesto por el Consejo antes del 31 de marzo de cada ańo. Si transcurrida dicha fecha no se ha cumplido la previsión constitucional, el presidente de la República puede disolver directamente el Parlamento y convocar nuevas elecciones. Es decir, no solo un órgano con una falta de democraticidad abismal puede vetar decisiones políticas de tanta trascendencia como son las presupuestarias, sino que puede incluso forzar la disolución del Poder Legislativo y crear, con ello, una crisis constitucional de calibre y de imprevisibles consecuencias (Gabor Attila, 2012: 316).

El reto que supone el Consejo Presupuestario húngaro para la democracia constitucional y el principio de legitimidad es evidente y, sobre todo, preocupante. La radicalidad del planteamiento institucional que ha realizado Hungría en su Constitución, que, incluso, ha sido denunciado por la OCDE (2012: 17), pone en entredicho los principios basilares en los que descansan nuestros sistemas democráticos. La función presupuestaria del Parlamento en uso de la representación política legítimamente constituida es sustituida por la interpretación de un órgano independiente de expertos con mandatos extensísimos que pueden servirse, sin rendir cuentas, de una discrecionalidad amparada en los ambiguos y abiertos conceptos que rodean la BBR. Es más, ni siquiera podemos afirmar que tal configuración institucional pudiera contentar a los sectores más intransigentes de la escuela de la economía constitucional, pues aquí el criterio de la unanimidad, o de lo más cercano a la misma, es sustraído de su ejercicio democrático por un eforado con pretensiones de tecnicidad. Más cercana a los postulados de Buchanan, por el contrario, hubiera sido la elección por parte del constituyente húngaro de un órgano como el Consejo suizo (art. 159.3c de la Constitución Federal), dotado de competencias de control sobre los presupuestos federales y cuyo rechazo a los mismos ha de forzar mayorías cualificadas de aprobación en el Parlamento, que siempre tendrá, no obstante, la última voz.

\section{CONCLUSIONES}

A lo largo de las páginas precedentes hemos podido comprobar cómo, sirviéndose del contexto normativo e institucional norteamericano, se ha ido consolidando tanto en este como en las elaboraciones doctrinales de la economía constitucional una serie de mecanismos constitucionales tendentes a la 
restricción del margen de discrecionalidad fiscal y presupuestaria de los Estados. La estabilidad presupuestaria, nuevo principio vertebrador en la Unión Europea y en los Estados miembros a través de sus recientes constitucionalizaciones, es utilizada como parapeto teórico y jurídico para explorar vías alternativas, y ajenas a ella, de limitar las posibilidades de concreción que permitían las viejas constituciones económicas. Estas, arraigadas en el marco del Estado social que impelía a la apertura desde la que operaba el pluralismo político, se ven alteradas mediante la hipertrofia de instrumentos que buscan proteger el statu quo frente a los vaivenes políticos de las cambiantes mayorías sociales que se alternan en el poder.

La concurrencia en la determinación de las decisiones fiscales y presupuestarias de instrumentos de democracia semidirecta, mayorías cualificadas, excepciones procedimentales, organismos independientes de control con poder de veto o fondos de reserva, supone una mayor petrificación de la constitución económica apriorísticamente establecida en la norma fundamental, cuya indisponibilidad para la política diaria y especial eficacia normativa proyectan nuevas exigencias y virtualidades jurídicas para los poderes constituidos. Si la norma general en las decisiones político-económicas, tal y como podemos apreciar en el título VII de la Constitución espańola, había sido siempre la mayoría simple sin más limitaciones que las expresamente indicadas por la Constitución en un marco aperturista y alentador del pluralismo, los nuevos mecanismos dificultan la plena operatividad de este al volver más complejos los procedimientos democráticos, detraer automáticamente fondos económicos o reservar la última decisión a órganos ajenos al Parlamento. En este sentido, del conjunto de previsiones analizadas la que más llama la atención por las repercusiones que pueda tener para los principios de nuestra democracia constitucional es, sin duda, la que se refiere a la creación en Hungría, ex constitutione, de un nuevo Consejo Presupuestario independiente con poder de veto absoluto sobre las decisiones del Parlamento. El húngaro constituye un caso único en el derecho comparado y lleva hasta el extremo los presupuestos teóricos de la economía constitucional y las pretensiones normativas de la Revolt Tax estadounidense, hasta el punto de poder contravenir las reglas más esenciales y basilares del principio democrático.

La posibilidad de que el «nuevo» conjunto de mecanismos constitucionales de limitación del poder fiscal y presupuestario se implante en Europa, al calor de la gobernanza económica de la UE y la consagración en su seno de la estabilidad presupuestaria, no es tan alejada como se pueda suponer. Su desembarco a este lado del Atlántico ya se ha iniciado, aunque haya tomado la forma de una radicalidad inesperada hasta para los propios teóricos de la economía constitucional y los defensores a ultranza de la Golden Rule. 


\section{Bibliografía}

Adams, M., Fabbrini, F. y Larouche, P. (eds.) (2014). The Constitutionalization of European Budgetary Constraints. Hart Publishing.

Asatryan, Z., Castellón, C. y Stratmann, T. (2016). Balanced Budget Rules and Fiscal Outcomes: Evidence from Historical Constitutions. Center for Economics Studies Working Paper, 5893.

Brennan, G. (1981). Tax limits and the logic of constitutional restrictions. En H. Ladd y A. Brennetot (2015). The geographical and ethical origins of neoliberalism: The Walter Lippmann Colloquium and the foundations of a new geopolitical order. Political Geography, 49, 30-39.

Brennan, G. y Buchanan, J. M. (1987). El poder fiscal. Fundamentos analiticos de una constitución fiscal. Madrid: Unión Editorial.

Buchanan, J. M. (1975). Utopia, the Minimal State, and entitlement. Public Choice, 23 (1), 121-126.

- (1995). Clarifying Confusion About the Balanced Budget Amendment. National Tax Journal, 48, (3), 350.

(2009). Los limites de la libertad. Entre la anarquia y el Leviatán. Madrid: Katz Editores.

Cain, B. y Noll, R, (2010). Institutional causes of California's Budget Problem. Stanford Institute for Economic Policy Research, 10.

Casas Pardo, J. (2011). La filosofía económica de James M. Buchanan. Anuario filosófico, 44 (2), 233.

Crozier, M., Huntington, S. H. y Watanuki, J. (1975). The Crisis of Democracy: On the Governability of Democracies. New York: New York University Press.

Elster, J. y Slagstad, R. (eds.) (1988). Constitutionalism and Democracy. Cambridge: Cambridge University Press.

Embid Irujo, A. (2012). La constitucionalización de la crisis económica. Madrid: Iustel

Escalante Gonzalbo, F. (2016). Historia minima del neoliberalismo. Madrid: Editorial Turner.

Gabor Attila, T. (ed.). Constitution for a disunited nation: On Hungary's 2011 Fundamental Law. Budapest: Central European University Press.

Gardner, J. A. (1996). The "State-as-Laboratories" Metaphor in State Constitutional Law. Valparaiso University Law Review, 30 (2), 475-491.

Gorospe Oviedo, J. I. (2012). La estabilidad presupuestaria de las comunidades autónomas y la reforma del artículo 135 CE. En E. Álvarez Conde y C. Souto Galán (coords.) La constitucionalización de la estabilidad presupuestaria (pp. 339-372). Madrid: Universidad Rey Juan Carlos.

Guerrero Vázquez, P. (2016). Freno al endeudamiento autonómico y coerción estatal en la Ley Orgánica de Estabilidad Presupuestaria y Sostenibilidad Financiera. Revista general de derecho constitucional, 23.

Kiewiet, R. y Szakaly, K. (1996). Constitutional Limitations on Borrowing: An Analysis if State Bonded Indebtedness. California Institute of Technology, 65.

Kuttner, R. (1980). Revolt of the Haves: Tax Rebellions and Hard Times. New York: Simon and Schuster.

Kyvig, D. E. (1995). Refining or Resisting Modern Government? The Balanced Budget Amendment to the U.S. Constitution. Akron Law Review, 28 (2). 
Linde Paniagua, E. (2012). La mutación de la Unión Europea y de su derecho originario: la modificación del artículo 136 del TFUE, y otros tratados (tratados parásitos) suscritos por estados de la Unión Europea, en particular, el tratado de estabilidad, coordinación y gobernanza en la Unión Europea. Revista de derecho de la Unión Europea, 23, 87-104.

Matsusaka, J. G. (2004). For the Many or the Few: The Initiative, Public Policy, and American Democracy. Chicago: The University of Chicago Press.

— (2005a). Direct Democracy Works. Journal of Economic Perspectives, 19 (2), 185-206.

- (2005b). Direct Democracy and Fiscal Gridlock: Have Voter initiatives Paralyzed the California Budget? State Politics and Policy Quarterly, 5 (3), 248-264.

Moreno González, G. (2017a). La teoría de la Constitución en James Buchanan: hacia un modelo de economía constitucional. Revista de Estudios Políticos, 177, 57-88.

- (2017b). La constitucionalización de la estabilidad presupuestaria en Estados Unidos: lecciones de un debate inacabado. Estudios de Deusto, 65 (2), 247-288.

Morgan, I. (1988). Unconventional Politics: The Campaign for a Balanced Budget Amendment. Constitutional Convention in the 1970s. Journal of American Studies, 32, 422 y ss.

Munro, W. (1912). The Initiative, Referendum, and Recall. New York: D. Appleton.

O'Sullivan, A., Sexton T. y Sheffrin, S. (1999). Proposition 13: Unintended Effects and Feasible Reforms. National Tax Journal, 55.

OECD (2012). Economic Surveys: Hungary 2012.

Poterba, J. (1994). State Responses to Fiscal Crises: The Effects of Budgetary Institutions and Politics. Journal of Political Economy, 102 (4), 799-821.

Puy Fraga, P. (1996). Economía politica del Estado constitucional. Fundamentos de la Economía constitucional. Barcelona: Cedecs Editorial.

Rodríguez-Tejedo, I. (2012). The Determinants of the Structure of Rainy Day Funds. Public Administration Review, 72, (3), 76-386.

Rose, S. (2008). The Political Manipulation of U.S. State Rainy Day Funds Under Rules Versus Discretion. State Politics and Policy Quarterly, 8 (2), 150-176.

Tarr, A. (2001). Laboratories of Democracy? Brandeis, Federalism and Scientific Management. The Journal of Federalism, 37.

Vallespín Oña, F. (1985). Nuevas teorias del contrato social: John Rawls, Robert Nozick y James Buchanan. Madrid: Alianza Editorial.

Varju, M. (2012). Governance, Accountability, and the Market. En T. Gabor Attila (ed.). Constitution for a disunited nation: On Hungary's 2011 Fundamental Law (pp. 301333). Budapest: Central European University Press.

Wagner, G. A. y Russell S. (2006). State Budget Stabilization Fund Adoption: Preparing for the Next Recession or Circumventing Fiscal Constraints? Public Choice, 126 (2), 177-200.

Wagner, G. A. y Elder, E. M. (2007). Revenue Cycles and the Distribution of Shortfalls in U.S. States: Implications for an "Optimal" Rainy Day Fun. National Tax Journal, 60 (4).

Zipfel, F. (2011). Stability Council: Financial Inspector of Germany's Lander. Frankfurt: Deutsche Bank Research. 